\title{
A FRAMEWORK FOR THE EVALUATION OF HOTEL PROPERTY DEVELOPMENT PROJECTS
}

\author{
Gabrijela POPOVIC ${ }^{1, *}$, Dragisa STANUJKIC ${ }^{2}$, Darjan KARABASEVIC 3 \\ ${ }^{1}$ Faculty of Management in Zajecar, Megatrend University, Belgrade, Serbia \\ ${ }^{2}$ Technical Faculty in Bor, University in Belgrade, Belgrade, Serbia \\ ${ }^{3}$ Faculty for Applied Management, Economics and Finance, Business Academy University, Belgrade, Serbia
}

Received 11 July 2017; accepted 17 January 2018

\begin{abstract}
The main goal of the manuscript is to propose the framework that would facilitate the selection of hotel construction projects for an investment based on the application of the WS PLP method. The key reason why the WS PLP method is used is reflected in its ability to more accurately express decision-makers' stand regarding the desired preference ratings of criteria by incorporating ppr values into the decision-making process. Also, the WS PLP method implies the introduction of the compensation coefficient, which provides a possibility of the decision-maker's selection between an alternative that has the best matching with the preferred performance ratings expressed through ppr values and the one that has the best overall performance ratings. The applicability and effectiveness of the proposed framework are demonstrated through a real case study on the five types of the hotels that should be constructed on Kopaonik Mountain in Serbia.
\end{abstract}

Keywords: MCDM, WS PLP method, hotel, construction projects, investment.

\section{Introduction}

Investment projects are conducted for the purpose of achieving the desired goals that will bring benefits in a future period with respect to the two main factors: the cost and time. Investment in real estate is certainly a specific kind of investment which implies the construction of a new commercial or residential type of buildings.

According to Newell and Seabrook (2006), hotel properties represent the important property investment sector that belongs to the nonresidential type of real estate, have the specificities that distinguish them from the other types of real estate and require unique management expertise. Investment in hotels is a high-risk investment because the return on investment depends on both the real estate market and the tourism market, which are very unpredictable and volatile. This risk, caused by the sensitivity of investment return to the changing conditions of the local and national market economies, is systematic and not easy to manage.

Hotel construction and development is a very important issue and represents the first phase in the lifecycle of a hotel. Hotel development often implies the development of a hotel's property or hotel business; there is, however, a clear distinction between them (Cloete \& Venter, 2013). The crucial characteristic of hotel investment is the large cost of construction that affects decisions on the size of the desired building. Because of that, the investor has to consider different aspects of the problem in order to find the best alternative and make the most appropriate choice.

An investor who wants to invest in the project of the construction of a hotel usually has limited financial resources and two or more alternatives, between which he/ she has to choose. Making a decision on the project that should be invested in is not a simple task, whereas the risk of investment is relatively high and the final business result is uncertain. The criteria involved in the decisionmaking process are often conflicting and the prioritizing of one type of them usually leads to a situation in which others are neglected. Because of the complex nature of the problem of the selection of hotel construction projects, the Multiple Criteria Decision Making (MCDM) methods could provide an adequate solution relying on all of the considered criteria, regardless of their type.

This manuscript is aimed at providing an effective MCDM approach, based on the Weighted Sum method adapted for the purpose of the analysis based on the decision-maker's $(D M)$ preferences for the selection of the most acceptable alternative, i.e. in this case, for the appropriate hotel construction project adequate for being invested in.

${ }^{*}$ Corresponding author. E-mail: gabrijela.popovic@fmz.edu.rs 
The framework is tested by using a real case study inclusive of Kopaonik Mountain in Serbia, where the construction of five different types of hotels is planned. The evaluation and selection of the appropriate construction projects relies on the four criteria because the original intention is to indicate the applicability of the proposed framework without the involvement of a large number of the criteria that will complicate the computational procedure.

Therefore, the manuscript is structured as follows: in Section 1, a literature review is presented. Then, the framework for evaluating the hotel construction projects based on the WS PLP method is given in Section 2. Section 3 contains a case study inclusive of the explanation of the considered problem. The application of the proposed framework is demonstrated in Section 4, with the aim to emphasize the advantage of the proposed methodology. Finally, the conclusions are given in the last section.

\section{Literature review}

The real-estate aspects of hotels and hotel construction issues are still an understudied scientific area (Manning et al., 2015) and there is a need for detailed research and observation therein. The main challenge in the field of construction projects, i.e. in the area of hotel construction projects, is the selection of an appropriate project that will be invested in and realized. If a decision is based on the expected revenue and if the same is made by a single $D M$, that would be an easy decision. Would such a decision, however, be right and appropriate for the present conditions without taking into account other criteria, such as technical, non-technical, financial, etc. ones? The DM who wants to invest in this kind of projects usually has a limited amount of financial resources and a bad decision could even lead to bankruptcy. Because of that, a need for applying mathematical and statistical methods, such as MCDM methods that could be a helpful tool in making an adequate decision, arises.

MCDM is a very important and often used decisionmaking procedure representing the fastest-growing field of management science. The MCDM implies the presence of a number of usually conflicting criteria affecting the final decision. The decision-making process is facilitated by using the developed MCDM procedures that enable us to involve every single conflicting criterion. Numerous procedures are proposed for solving a number of different decision-making problems. Some of those procedures are: SAW or WS (Churchman \& Ackoff, 1954; Fishburn, 1967), AHP (Saaty, 1980), TOPSIS (Hwang \& Yoon, 1981), PROMETHEE (Brans \& Vincke, 1985), ELECTRE (Roy, 1991), COPRAS (Zavadskas, Kaklauskas, \& Sarka, 1994) and VIKOR (Opricovic, 1998). Nowdays, a new generation of the MCDM methods is developed, such as: ARAS (Zavadskas \& Turskis, 2010), MULTIMOORA (Brauers \& Zavadskas, 2010), SWARA (Keršuliene, Zavadskas, \& Turskis, 2010), WASPAS (Zavadskas, Turskis, Antucheviciene, \& Zakarevicius, 2012), WS PLP (Stanujkic \& Zavadskas, 2015), and so on. In order to solve problems often associ- ated with predictions, vagueness, uncertainty and imprecision, the above-mentioned methods have developed appropriate extensions through applying fuzzy, intuitionistic fuzzy or grey numbers.

As has previously been said, a framework for the selection of an optimal hotel construction project to invest in is proposed in this manuscript. The aforementioned framework is based on the newly-developed Weighted Sum method, based on the decision-maker's Preferred Levels of Performances (WS PLP), which is the improved Weighted Sum (WS) or the Simple Additive Weighted (SAW) method. The WS or SAW method is a very simple method frequently used in the past in order to solve different kinds of decision-making problems, such as: the location selection (Chou, Chang, \& Shen, 2008; Jeong, García-Moruno, \& Hernández-Blanco, 2013), the ranking of transportation zones (Jakimavičius \& Burinskiene, 2009), the personnel selection (Afshari, Mojahed, \& Yusuff, 2010), the assessment of power supply technologies (Shakouri, Nabaee, \& Aliakbarisani, 2014), the assessment of the environmental risk and sustainability of projects (Rikhtegar et al., 2014; Oltean-Dumbrava, Watts, \& Miah, 2016) and dealing with problems in a fuzzy environment (Kabak \& Ruan, 2011; Chen, 2012; Wang, 2015; P. Wang, Zhu, \& Y. Wang, 2016).

In the area of the hotel industry, the MCDM methods are often used for the assessment of the service quality (Hsieh, L.-H. Lin, \& Y.-Y. Lin, 2008; Tseng, 2009; Shirouyehzad, Lotfi, Arabzad, \& Dabestani, 2013), the evaluation of the energy efficiency of hotel buildings (Xu \& Chan, 2013), the selection of a marketing strategy (Lin, Lee, \& Wu, 2009; Wu, Lin, \& Lee, 2010; Varini, Scaglione, \& Schegg, 2011), the location selection (Li, Law, Vu, \& Rong, 2013; Emir \& Saraçli, 2014; Krylovas, Zavadskas, \& Kosareva, 2016; Aksoy \& Ozbuk, 2017), the evaluation of the accommodation quality (Park, Kim, \& Choo, 2014), etc. The selection of the optimal hotel construction project to invest in by applying some MCDM methods is an interesting topic not fully considered in light of the newly-developed approaches. The authors have discussed the selection of construction projects and the key factors for their assessment that can be found in the manuscripts by Ustinovichius, Zavadkas, and Podvezko (2007), Ebrahimnejad, Mousavi, Tavakkoli-Moghaddam, Hashemi, and Vahdani (2012), Taylan, Bafail, Abdulaal, and Kabli (2014); however, when it comes to hotel construction projects, there is enough room for further research and analysis.

\section{A framework for the evaluation of hotel construction projects}

As has already been mentioned, the WS PLP method was introduced by Stanujkic and Zavadskas (2015). The main idea that had led to making a proposal for this new approach rests on the normalization procedure proposed by Stanujkic, Magdalinovic, and Jovanovic (2013) that takes into account the DM's preferences for preferred performance ratings ( $p p r)$. The $p p r$ value is the desired value of the performance ratings of the observed criteria 
defined by the $D M$. Although every single MCDM method more or less incorporates the DM's attitudes, in the case of the WS PLP method, such attitudes are concretely expressed through the mentioned $p p r$ values, which are accurately defined and directly affect the final decision and the ranking order of the alternatives. By applying the WS PLP method, the set of the available alternatives is transformed into the set of more acceptable alternatives, and the optimal alternative should be selected from the second set.

In this method, the overall performance ratings of the considered alternatives which are equal to zero show that the performance ratings of these alternatives are equal to the desired $p p r$ values. The overall performance ratings greater than zero have the alternatives whose preference ratings exceed the $p p r$ values or the alternatives whose better performance ratings compensate for the impact of the worse performance ratings. The overall performance ratings of the alternatives could sometimes have high values because only one or a few criteria has/have a greater distance to the ppr values, which results in the better ranking of those alternatives. In order to overcome the possibility of the occurrence of this situation, the compensation coefficient reducing the overall performance ratings and fine-tuning the ranking order of such alternatives is introduced. This enables the $D M$ to make a distinction between the alternative with the highest ranking scores and that better matching the desired value of the criteria.

In the field of hotel construction projects, DMs mainly precisely know what he/she is required to do with respect to the main features of a hotel, and how many financial resources could be invested in the project. The possibility of expressing these requirements through the $p p r$ values contributes to making a proper decision and selecting the optimal hotel construction project to invest in. Beside that, $D M s$ could choose if they would like to give advantage to the hotel construction project that has the best possible overall performance rating or to that with a better matching with the desired $p p r$ values that are enabled by the introduction of the explained compensation coefficient. Also, $D M$ s could easily determine whether an alternative has a good ranking according to only one criterion or a few criteria with good parameters. In that way, the case of the selection of such a project that does not fulfill all or the majority of the set requirements could be avoided.

The selection of the optimal hotel construction project presented in this manuscript is performed by applying the original WS PLP method, introduced by Stanujkic and Zavadskas (2015), and its calculation procedure can precisely be presented through the following steps:

Step 1. The selection of the set of the representative criteria that describe the alternatives. As a result of these activities, the decision-making matrix $X$ can be created as follows:

$$
X=\left[\begin{array}{cccc}
x_{11} & x_{12} & \cdots & x_{1 n} \\
x_{12} & x_{22} & \cdots & x_{2 n} \\
\vdots & \vdots & \vdots & \vdots \\
x_{m 1} & x_{m 2} & \cdots & x_{m n}
\end{array}\right],
$$

where: $x_{i j}$ denotes the performance rating of the alternative $i$ with respect to the criterion $j$; $m$ represents the number of the alternatives and $n$ the number of the criteria.

Step 2. The definition of the weights of the criteria. The AHP method is used to define the weights of the criteria. In this case, group decision-making would be applied in order to gain the more appropriate weights of the considered criteria.

The consistency of the DM's answers is determined by using the consistency ratio $C R$ as follows:

$$
C R=C I / R I \text {, }
$$

where: $R I$ represents the random index that depends on the number of the criteria involved in the decision-making process. If the value of $C R$ is 0.1 or less than that, it is then considered as acceptable and reflects an appropriate judgment. The weights of the criteria are properly determined if the condition $C R>0$ is fulfilled.

The consistency index $C I$ is determined by using Eq. (3):

$$
C I=\left(\lambda_{\max }-m\right) /(m-1),
$$

where: $\lambda_{\max }$ is the maximal Eigenvalue.

The relative normalized weight of each criterion is calculated by using Eqs (4) and (5):

$$
\begin{aligned}
& G M_{j}=\left(\prod_{k=1}^{K} w_{j}^{k}\right)^{1 / K}, \\
& w_{j}=G M_{j} / \sum_{l=1}^{n} G M_{l},
\end{aligned}
$$

where: $G M_{j}$ represents the geometric mean of the weights obtained from the DMs involved in the evaluation of the criterion $j ; w_{j}$ denotes the weights of the criterion $j$ and $K$ is the number of $D M$ s.

Step 3. The definition of the ppr value for each criterion. This step implies the determination of the $p p r$ values according to the DM's preferences, which represents the elements of the virtual alternative $A_{0}=\left\{x_{01}, x_{02}, \ldots, x_{0 n}\right\}$. If the $p p r$ value of any criterion is not determined by the $D M$, then it is defined as follows:

$$
x_{0 j}=\left\{\begin{array}{l}
\max _{i} x_{i j} \mid j \in \Omega_{\max } \\
\min _{i} x_{i j} \mid j \in \Omega_{\min }
\end{array},\right.
$$

where: $x_{0 j}$ denotes the optimal ppr of the criterion $j ; \Omega_{\max }$ and $\Omega_{\text {min }}$ are a set of the benefit and the cost criteria, respectively.

Step 4. The formation of the normalized decisionmaking matrix. For that purpose, the normalization procedure that allows $D M s$ to better express their preferences for the $p p r$ proposed by Stanujkic et al. (2013) is used by applying Eqs (7) and (8):

$$
\begin{aligned}
& r_{i j}=\frac{x_{i j}-x_{j}^{*}}{x_{j}^{+}-x_{j}^{-}} ; j \in \Omega_{\max }, \text { and } \\
& r_{i j}=\frac{x_{j}^{*}-x_{i j}}{x_{j}^{+}-x_{j}^{-}} ; j \in \Omega_{\min },
\end{aligned}
$$


where: $r_{i j}$ is the normalized performance rating of the alternative $i$ with respect to the criterion $j ; x_{j}^{*}$ denotes the ppr value of the criterion $j$, and $x_{j}^{+}$and $x_{j}^{-}$represents the largest and the smallest performance ratings of the criterion $j$, respectively.

Step 5. The calculation of the overall performance rating for each alternative. Eq. (9) is used for the purpose of calculating the overall performance ratings:

$$
S_{i}=\sum_{j=1}^{n} w_{j} \cdot r_{i j}
$$

where: $S_{i}$ represents the overall performance rating of the alternative $i$, and and $S_{i} \in[0,1]$.

When the overall performance ratings for two or more alternatives are higher than $0\left(S_{i}>0\right)$, the calculations should be continued through the following steps. In the opposite case, the optimal alternative is the one with the largest $S_{i}$, and such alternatives are ranked in ascending order. If the procedure ends in this step, the gained ranking order is, in that case, the result of the application of the ordinary WS method, which is a segment of the newlyproposed WS PLP method.

Step 6. The calculation of the compensation coefficient. The compensation coefficient should be calculated for all the alternatives in which $S_{i}>0$, as follows:

$$
c_{i}=\lambda d_{i}^{\max }+(1-\lambda) \bar{S}_{i}^{+},
$$

where:

$$
\begin{aligned}
& d_{i}^{\max }=\max _{i} d_{i}=\max _{i} r_{i j} w_{j} ; \\
& \bar{S}_{i}^{+}=\frac{S_{i}^{+}}{n_{i}^{+}},
\end{aligned}
$$

where: $d_{i}^{\max }$ represents the maximum weighted normalized distance of the alternative $i$ relative to the $p p r$ values of all the criteria so that $r_{i j}>0 ; \bar{S}_{i}^{+}$represents the average performance ratings achieved on the basis of the criteria so that $r_{i j}>0 ; n_{i}^{+}$represents the number of the criteria of the alternative $i$ so that $r_{i j}>0 ; \lambda$ is the coefficient $(\lambda=[0,1])$ and is usually set at 0.5 .

Step 7. The calculation of the adjusted performance rating. The adjusted performance rating should be calculated for all the alternatives in which $S_{i}>0$ by using Eq. (13):

$$
S_{i}^{\prime}=\sum_{j=1}^{n} w_{j} r_{i j}-\gamma c_{i},
$$

where: $S_{i}^{\prime}$ represents the adjusted overall performance rating of the alternative $i ; c_{i}$ is the compensation coefficient $\left(c_{i}>0\right)$; and $\gamma$ represents the coefficient $(\gamma=[0,1])$.

Step 8 . The ranking of the alternatives and the selection of the most suitable one. The most acceptable alternative is the one whose $S_{i}^{\prime}$ value is the largest and alternatives are ranked in ascending order.

\section{A case study}

Kopaonik Mountain is the most popular and the most visited ski center in the Republic of Serbia. However, it lags behind its competitors in the neighboring countries, namely: Bulgaria, Slovenia and Bosnia and Herzegovina. In other to achieve the desired goals and accelerate the development of the mentioned mountain, the Ministry of Economy and Regional Development of the Republic of Serbia entered into a contract with Ecosign Mountain Resort Planners from Canada and Horwath Consulting from Croatia for the purpose of making a plan for tourism development on Kopaonik Mountain, which includes a pre-investment study and the consideration of the physical and technical characteristics of the ski resort. As a result, the Master Plan for Tourist Destination Kopaonik (Horwath HTL, 2009) has been made, containing an overview of the present state of the ski resort and the suggestions regarding the direction that should be followed in order to develop this mountain.

One part of the Master Plan contains a review of the key investment projects pointed out with respect to the construction of several types of accommodations. So far, 4,000 beds on Kopaonik have been estimated, so the construction of new accommodations would improve the overall accommodation offer. The existing tourist and accommodation capacities are not concurrent with the foreign and regional ski centers considered as the leaders in the field of mountain tourism.

The technical evaluation shows that there is a possibility of increasing the tourism capacity and accepting a larger number of skiers, which should be accompanied by increasing the number and quality of the accommodation units. This is impossible to achieve in a short period of time; so, the desired state could be achieved through the realization of the several phases that would acknowledge the present economic and market situation. Beside that, it is necessary to develop a stimulating environment to invest in, which is the key precondition for the successful achievement of the desired goals.

Three phases consisting of certain sub-phases are proposed in the aforementioned Master Plan because of the complexity and abundance of the anticipated engagement. In each phase, the construction of a certain number of the accommodation facilities that will provide adequate conditions for attracting tourists and contribute to the competitiveness of the considered mountain is planned. The anticipated types of accommodations and their main characteristics are accounted for below, as follows:

Destination Hotel. A four-star hotel intended for vacation, seminars and meetings. Comfortable accommodation units will be designed only for commercial use. There will be no possibility of selling accommodation units on the real estate market. The destination hotel would have a swimming pool, a commercial and service offer for skiers.

Boutique Hotel. A four-star-plus or five-star hotel intended for single users or families who opt for shorter or longer stays. It will be a smaller luxury building, with a few accommodation units leaning upon the contents at the "Village Center". It will only be used for commercial purposes. 
Condo Hotel. A three- or four-star hotel, with or without a condominium, intended for single users or families. The building will include a few accommodation units that will, first, be sold on the real estate market and then commercially used. The hotel will be leaning against the commercial center and relying on other resort offers.

Townhouse. Three-star-plus privately-owned houses for the accommodation of several families. There will be a few accommodation units per building intended for sale on the real estate market and for commercial use.

Chalet. Three-star-plus or four-star houses intended for the accommodation of a single family, only for users with higher earnings, capable of affording them. Every chalet will have two floors, a certain number of rooms and a private parking lot, and will be intended for sale on the real estate market, as well as for commercial use.

The detailed projections about the presented types of accommodation facilities as well as their development through the planned phases can be found in the aforementioned Master Plan (Horwath HTL, 2009). Due to extensiveness, only the data needed for the presentation of the applicability of the proposed framework are shown in this manuscript (Table 1).

The data shown in the Table 1 stand for the projected parameters of the construction of a certain type of accommodation facilities on Kopaonik Mountain. These data take into consideration the fact that the development of the accommodation capacities should be carried out through several phases and are not strictly bound to any one of them. The given values are estimated by using data about similar accommodations and by analyzing similar projects in the Southeast European region, taking into account the conditions on the local market.

As can be inferred, big and expensive investment projects are in question. The fact that the financial resources are limited emphasizes the importance of appropriate decisions on the selection of the optimal hotel construction project to be invested in. Each of the aforementioned projects requires significant investment per $\mathrm{m}^{2}$ and it is understandable that one single investor could not invest in all of them. Also, the above-mentioned projects differ from each other with respect to the listed characteristics. Therefore, it is very important that every available alterna- tive should be assessed from different aspects and that the final decision should be made. For all the foregoing reasons, the use of the MCDM methods, particularly the WS PLP for the selection of an appropriate hotel construction project to invest in is entirely justified.

The starting point in the selection of the optimal hotel construction project to invest in is surely defining the set of the criteria that will be the base for a further evaluation. The authors have proposed a different combination of the criteria for the evaluation of investment in the real estate property that could be applied in the field of hotel construction as well. A good example of that is certainly the manuscript by Zavadskas, Ustinovichius, and Stasiulionis (2004) that provides us with an extensive overview and a clear explanation of the aspects important for the valuation of commercial construction projects to invest in. Beside that, the manuscripts by Ginevičius and Zubrecovas (2009) and Ha, Jeong, and Lee (2015) also suggest a set of the criteria that could be used in the evaluation and selection of the optimal real estate, i.e. the optimal business hotel to invest in.

According to the Ginevičius and Zubrecovas (2009), the selection of a real estate investment project is based on the two different groups of criteria, which are as follows: the project environment criteria and the project economic efficiency criteria. The group of the criteria marked as the project environment criteria consists of the following subgroups: the legal environment criteria, the territory attractiveness criteria and the business perspectives criteria. The group of the economic efficiency criteria includes the following sub-groups: the financing criteria, the financial criteria and the financial efficiency criteria. Each of the aforementioned sub-groups involved a great number of the more detailed criteria that stress the different aspects of the considered project. For example, the economic efficiency of a project could be described by 43 criteria, but, observing the expert opinions, Ginevičius and Zubrecovas (2009) shortened this list by reducing it to only 15 such criteria.

Ha et al. (2015) organized the criteria important for the selection of the appropriate business hotel to invest in into 3 groups, namely: the social and locational environment, the investment environment and the condition of

Table 1. The projected data for different types of hotels (source: Horwath HTL, 2009)

\begin{tabular}{|l|c|c|c|c|c|}
\hline & $\begin{array}{c}\text { Destination } \\
\text { hotel }\end{array}$ & $\begin{array}{c}\text { Boutique } \\
\text { hotel }\end{array}$ & $\begin{array}{c}\text { Condo } \\
\text { hotel }\end{array}$ & Townhouse & Chalet \\
\hline Accommodation units per ha of parcel & 100 & 100 & 100 & 25 & 10 \\
\hline Surface of accommodation unit $\left(^{2}\right)$ & $30-80$ & $65-85$ & $40-80$ & $70-90$ & $100-130$ \\
\hline Investment per $m^{2}$ of gross developed surface (EUR) & $900-950$ & $900-1100$ & $800-900$ & $850-950$ & $900-1000$ \\
\hline Average selling price per $m^{2}$ of accommodation unit (EUR) & - & - & 1450 & 1900 & 1800 \\
\hline Number of working days per year & 300 & 365 & 300 & 300 & 300 \\
\hline $\begin{array}{l}\text { Number of days per year when accommodation is used by } \\
\text { owners }\end{array}$ & - & - & 40 & 50 & 60 \\
\hline $\begin{array}{l}\text { Average realized price of accommodation unit for overnight } \\
\text { staying (EUR) }\end{array}$ & 120 & 140 & $85-103$ & $100-121$ & $170-206$ \\
\hline
\end{tabular}


a prospective property. The group of the social and locational environment contains three sub-groups, which are as follows: the locational condition, the market environment and the business environment. The second group marked as the investment environment also involves three sub-groups, which are as follows: investment economic feasibility, the qualification of the financial structure and investment risk factors. In the end, the third group pointing to the condition of prospective property includes: the facility size, design and the hotel demand status. Each one of the mentioned sub-groups is further elaborated into a larger number of the more detailed criteria.

As can be seen, the basic dimensions (the groups and sub-groups of the criteria) proposed for the project selection in the field of real estate investment is principally coincident. The main question, however, is how the appropriate number of the detailed criteria adequate for the considered decision-making problem should be determined. Each one of above-mentioned dimensions could be described by a different combination of criteria, and which combination of the criteria is the most suitable to apply is very difficult to define. In that case, the utilization of the principal component analysis (PCA) or the factor analysis would be very useful.

The PCA and the factor analysis are often seen as similar techniques, but they are quite different. Both have the same goal to reduce the dimensionality of a data set, but their approaches are very distinct from each other (Jolliffe, 1986). In order to extract the main information from a data set, the PCA, introduced by Hotelling (1933), computes the new variables, called principal components, which represent the linear combinations of the original variables (Abdi \& Williams, 2010). Contrary to the PCA that accounts for the total variance of variables, the factor analysis (Spearman, 1904; Thurstone, 1935, 1947) is focused on the distinction of the least number of the factors that could account for the common variance shared by a set of variables and it does not differentiate between the unique variance and the error variance to reveal the underlying factor structure (Costello \& Osborne, 2005). The factor analysis involves the two main techniques, namely: Exploratory Factor Analysis (EFA) and Confirmatory Factor Analysis (CFA). In order to confirm hypotheses and represent the factors and the variables, the EFA uses path analysis diagrams. On the other hand, the CFA is focused on testing predictions and exploring a data set in order to reveal complex patterns (Child, 2006). Both the PCA and the factor analysis would contribute to the compilation of a list of the crucial criteria which decision-making connected to the selection of a hotel construction project should be based on.

The proposed lists of the criteria in the above-mentioned manuscripts are significant and the use of any one of them would generate quite an extensive numerical example. Because of that, in this case, selection is based on the set of the criteria retrieved from the above-mentioned Master Plan for tourism development on Kopaonik Mountain, which is in compliance with that proposed by the aforementioned authors, and best suits within the groups of the criteria proposed by Ha et al. (2015), namely: the investment environment and the condition of a prospective property. The criteria connected to the dimensions of the projects such as the social and locational environment, the business environment, the territory attractiveness and the legal environment are not involved in the model because it started from the assumption that $D M$ s had already decided to build a hotel on Kopaonik Mountain in Serbia. The initial idea is to demonstrate the applicability of the proposed framework that could be used for the assessment of any kind of criteria the $D M$ may be concerned about on the simple numerical example not burdened with a large number of criteria.

\section{The application of the proposed framework}

In this section, the application of the proposed framework pointed to the selection of the optimal hotel construction project to be invested in is considered in order to demonstrate and explain the proposed approach. The demonstration of the proposed methodology is based on the data taken from Table 1, which is slightly modified. The modification is reflected in the fact that Table 1 accounts for the interval values for certain criteria involved in the decision-making process, such as e.g. the surface of the accommodation unit expressed in $\mathrm{m}^{2}$. Because the proposed framework is based on the use of crisp numbers, the average values for the criteria with the interval type of data are determined. So, the five different hotel construction projects and the four criteria against which evaluation will be performed are presented in Table 2.

Table 2. Raw data

\begin{tabular}{|c|l|c|c|c|c|}
\hline \multirow{2}{*}{ Alternatives } & $\begin{array}{c}\text { Criteria } \\
\text { Accommodation units } \\
\text { per ha of parcel }\end{array}$ & $\begin{array}{c}\text { Surface of } \\
\text { accommodation unit } \\
\left(\mathrm{m}^{2}\right)\end{array}$ & $\begin{array}{c}\text { Investment per m }{ }^{2} \text { of } \\
\text { gross developed surface } \\
\text { (EUR) }\end{array}$ & $\begin{array}{c}\text { Average realized price of } \\
\text { accommodation unit for } \\
\text { overnight staying (EUR) }\end{array}$ \\
\hline$A_{1}$ & Destination hotel & $C_{1}$ & $C_{2}$ & $C_{3}$ & 120 \\
\hline$A_{2}$ & Boutique hotel & 100 & 55 & 925 & 140 \\
\hline$A_{3}$ & Condo hotel & 100 & 75 & 850 & 94 \\
\hline$A_{4}$ & Townhouse & 25 & 80 & 900 & 111 \\
\hline$A_{5}$ & Chalet & 10 & 115 & 950 & 180 \\
\hline
\end{tabular}


Each of the listed accommodations has its own characteristics that distinguish it from the others from the economic and technical points of view and represent the criteria the evaluation process will be based on. As noted earlier, in order to demonstrate the applicability of the proposed WS PLP method only four criteria are used in this manuscript; depending on the needs, however, a larger number of the criteria can also be involved.

In order to determine the weights of the proposed criteria, three $D M$ s (hereinafter $D M_{1}, D M_{2}$ and $D M_{3}$ ) were consulted. The incorporation of a larger number of $D M s$ in the decision-making process contributes to the reduction in the subjectivity of the results obtained. Namely, introducing a certain amount of the subjectivity into decision-making process is inevitable; by incorporating group decision-making, however, such subjectivity could be reduced to an acceptable level. The pairwise matrix for $D M_{1}, D M_{2}$ and $D M_{3}$, as well as the $C R$, that confirms the existence of the consistency of the results obtained are presented in Tables 3-5.
Based on the data presented in Tables (3)-(5) the single weights of the criteria according to the $D M_{1}, D M_{2}$ and $D M_{3}$ and the overall weights of the criteria calculated by using Eqs. (4) and (5) are shown in Table 6.

According to Table 6, each DM determined a different weight of the considered criteria. Because their standpoints and opinions are so diverse, the obtained overall weights can be considered as more representative, which is achieved by incorporating the DMs' different judgments.

The performance ratings of the alternatives, the selected criteria, the previously determined weights of the criteria and the $p p r$ values that express the desired values of the considered criteria according to the DMs are shown in Table 7. In this case, the hypothetical ppr was defined from the investor's standpoint.

The normalized performance ratings, obtained by using Eqs (7) and (8), are accounted for in Table 8. The normalization procedure is conducted in order to reduce various measures to a single comparable measure.

Table 3. Pairwise matrix $-D M_{1}$

\begin{tabular}{|c|c|c|c|c|}
\hline & $C_{1}$ & $C_{2}$ & $C_{3}$ & $C_{4}$ \\
\hline$C_{1}$ & 1.000 & 3.000 & 0.200 & 0.143 \\
\hline$C_{2}$ & 0.333 & 1.000 & 0.143 & 0.143 \\
\hline$C_{3}$ & 5.000 & 7.000 & 1.000 & 1.000 \\
\hline$C_{4}$ & 7.000 & 7.000 & 1.000 & 1.000 \\
\hline
\end{tabular}

Table 4. Pairwise matrix $-D M_{2}$

\begin{tabular}{|c|c|c|c|c|}
\hline & $C_{1}$ & $C_{2}$ & $C_{3}$ & $C_{4}$ \\
\hline$C_{1}$ & 1.000 & 3.000 & 0.200 & 0.143 \\
\hline$C_{2}$ & 0.333 & 1.000 & 0.143 & 0.111 \\
\hline$C_{3}$ & 5.000 & 7.000 & 1.000 & 0.333 \\
\hline$C_{4}$ & 7.000 & 9.000 & 3.000 & 1.000 \\
\hline
\end{tabular}

Table 5. Pairwise matrix $-D M_{3}$

\begin{tabular}{|c|c|c|c|c|}
\hline & $C_{1}$ & $C_{2}$ & $C_{3}$ & $C_{4}$ \\
\hline$C_{1}$ & 1.000 & 7.000 & 0.333 & 1.000 \\
\hline$C_{2}$ & 0.143 & 1.000 & 0.143 & 0.333 \\
\hline$C_{3}$ & 3.000 & 7.000 & 1.000 & 3.000 \\
\hline$C_{4}$ & 1.000 & 3.000 & 0.333 & 1.000 \\
\hline
\end{tabular}

Table 6. The weights of the criteria

\begin{tabular}{|c|c|c|c|c|}
\hline & $D M_{1}$ & $D M_{2}$ & $D M_{3}$ & Overall $w_{j}$ \\
\hline$C_{1}$ & 0.097 & 0.090 & 0.239 & 0.137 \\
\hline$C_{2}$ & 0.051 & 0.044 & 0.056 & 0.054 \\
\hline$C_{3}$ & 0.407 & 0.291 & 0.522 & 0.423 \\
\hline$C_{4}$ & 0.445 & 0.574 & 0.183 & 0.386 \\
\hline
\end{tabular}


Table 7. The initial decision-making matrix

\begin{tabular}{|c|c|c|c|c|}
\hline & $C_{1}$ & $C_{2}$ & $C_{3}$ & $C_{4}$ \\
\hline Optimization & $\max$ & $\max$ & $\min$ & 0.386 \\
\hline$w_{j}$ & 0.137 & 0.054 & 0.423 & 120 \\
\hline $\mathrm{ppr}$ & 80 & 60 & 950 & 120 \\
\hline$A_{1}$ & 100 & 55 & 925 & 140 \\
\hline$A_{2}$ & 100 & 75 & 850 & 94 \\
\hline$A_{3}$ & 100 & 60 & 900 & 111 \\
\hline$A_{4}$ & 25 & 80 & 950 & 188 \\
\hline
\end{tabular}

Table 8 . The normalized performance ratings

\begin{tabular}{|c|c|c|c|c|}
\hline & $C_{1}$ & $C_{2}$ & $C_{3}$ & $C_{4}$ \\
\hline$A_{1}$ & 0.222 & -0.083 & 0.167 & 0.000 \\
\hline$A_{2}$ & 0.222 & 0.250 & -0.333 & 0.213 \\
\hline$A_{3}$ & 0.222 & 0.000 & 0.667 & -0.276 \\
\hline$A_{4}$ & -0.611 & 0.333 & 0.333 & -0.096 \\
\hline$A_{5}$ & -0.778 & 0.916 & 0.000 & 0.723 \\
\hline
\end{tabular}

The overall performance ratings and the ranking results calculated by using Eq. (9) are given in Table 9.

The obtained results presented in Table 9 are the basis for making a decision on whether to continue the procedure or not. As is previously stated, the following steps are acceptable to apply in the case of alternatives whose overall performance ratings are higher than 0 . Because the overall performance rating for alternative $A_{2}$ - Boutique Hotel - is lower than $0\left(S_{i}<0\right)$, it will not be included in the further procedure. The other alternatives meet the set requirement and will be included in further evaluation and selection. Were the ranking performed in this step (because the same relies on the original WS method), the alternative ranked the first would be alternative $A_{5}-$ Chalet.

Table 9. The ranking results obtained on the basis of $S_{i}$

\begin{tabular}{|c|c|c|}
\hline & $\mathrm{S}_{\mathrm{i}}$ & Rank \\
\hline$A_{1}$ & 0.097 & 3 \\
\hline$A_{2}$ & -0.015 & 5 \\
\hline$A_{3}$ & 0.206 & 2 \\
\hline$A_{4}$ & 0.038 & 4 \\
\hline$A_{5}$ & 0.222 & 1 \\
\hline
\end{tabular}

Table 10 demonstrates the ranking results based on the $S_{i}^{\prime}$ value, obtained by using Eqs (10)-(13), respectively, for $\gamma=1$ and $\lambda=0.5$.

Table 10 shows the ranking order achieved by applying the WS PLP method that highlights alternative $A_{1}-$ Destination Hotel - as the optimal selection. The given alternative matches best the set requirements expressed through the $p p r$ values. Only criterion $C_{2}$ - the surface of the accommodation units in $\mathrm{m}^{2}$ - is a little less than the anticipated $p p r$ value for that criterion (see Table 7); this situation, however, does not affect the final ranking order. The compensation coefficient is fully respected in this case $(\gamma=1)$, in which manner a priority is given to the alternative that matches best the previously defined $p p r$ values. Alternative $A_{5}$ - Chalet - is ranked the second because it significantly exceeds the set requirements for criteria $C_{2}$ - the surface of the accommodation units in $\mathrm{m}^{2}$ and $C_{4}$ - the average realized price of the accommodation unit for an overnight stay in EUR (which is confirmed by the data presented in Table 7), which generated the higher values of $d_{i}^{\max }, \bar{S}_{i}^{+}, c_{i}$ and eventually the slightly lower overall ranking results in the case of the DM's prioritizing of the one matching better the set requirements expressed through the $p p r$ values. Alternatives $A_{3}-$ Condo Hotel

Table 10 . The ranking results based on the $S_{i}^{\prime}$ value

\begin{tabular}{|c|c|c|c|c|c|c|c|c|}
\hline & $d_{i}^{\max }$ & $S_{i}^{+}$ & $n_{i}^{+}$ & $\bar{S}_{i}^{+}$ & $c_{i}$ & $S_{i}$ & $S_{i}^{\prime}$ & Rank \\
\hline$A_{1}$ & 0.071 & 0.101 & 2 & 0.051 & 0.061 & 0.097 & 0.0360 & 1 \\
\hline$A_{3}$ & 0.282 & 0.313 & 2 & 0.156 & 0.219 & 0.206 & -0.0132 & 3 \\
\hline$A_{4}$ & 0.141 & 0.159 & 2 & 0.080 & 0.110 & 0.038 & -0.0719 & 4 \\
\hline$A_{5}$ & 0.279 & 0.328 & 2 & 0.164 & 0.222 & 0.222 & 0.0002 & 2 \\
\hline
\end{tabular}


and $A_{4}-$ Townhouse are ranked the third and the fourth, respectively, because certain criteria have worse parameters than expected, which is confirmed by the data given in Table 7.

The influence of the compensation coefficient $\gamma$ on the final ranking order is shown in Table 11.

By varying the coefficient $\gamma$, the obtained results are different in some segments, which is confirmed by the results accounted for in the Table 11. In a situation when the DM does not take into consideration the compensation coefficient $(\gamma=0)$ and in that way prioritizes the alternative with higher overall performance ratings, the best-ranked alternative is alternative $A_{5}$ - Chalet. As is mentioned above, this alternative has the best overall performance ratings that exceed the DM's preferences expressed through the $p p r$ values. The situation is the same when the $D M$ sets the significance of the compensation coefficient at $\gamma=0.5$.

In both cases, alternative $A_{3}$ - Condo Hotel - is in the second place. Criterion $C_{3}$ - investment per $\mathrm{m}^{2}$ of gross developed surface in EUR contributes a great deal to this order, because investment in it is the lowest relative to the other alternatives, which contributes to the overall performance rating of the considered alternative. Alternative $A_{1}$ - Destination Hotel - ranks the third because the anticipated criteria performance ratings do not significantly exceed the performance ratings of the other alternatives, which results the way it does. In all the three situations (when $\gamma=0, \gamma=0.5$ and $\gamma=1$ ), alternative $A_{4}$ - Townhouse - ranks the last because it does not match well with the DM's preferences, nor does it match well with the good overall performance rating.

Therefore, the DM can make a choice whether he/she wants to select the alternative that matches best his/her requirements (the Destination Hotel in this case) or whether he/she wants to invest in the alternative characterized by the best overall performance ratings (the Chalet in the present situation). This is a very sensitive issue because, in some cases, the best ranking of a certain alternative could be the result of the very high performance rating of only one or a few criteria, whereas other criteria could be relatively low and even unsatisfactory to the $D M$. The advantage of introducing the compensation coefficient is exactly reflected in a possibility of checking whether the requirements expressed through ppr values are taken into consideration to a greater extent or not, i.e. if the DM's preferences towards the performance ratings of the criteria involved in the evaluation process are acknowledged. In that manner, decision-making based on a single criterion or a smaller number of the criteria with high performance ratings is avoided and decisions are more reliable and realistic.

\section{Conclusions}

The issue of the selection of the hotel construction project to invest in is very important because a successfully conducted investment will lead to the return of the invested financial resources, as well as to a future business operation success. Because decisions on construction projects, as well as those on hotel construction projects, are affected by many, often conflicting criteria, the application of the MCDM methods is entirely justified, which is confirmed in the manuscript by Jato-Espino, Castillo-Lopez, Rodriguez-Hernandez, and Canteras-Jordana (2014), who give an extensive overview of the MCDM methods used for the purpose of a project selection, as well as for the purpose of solving other issues within the construction field.

Authors have often applied MCDM methods for the purpose of selecting construction projects generally (see Ebrahimnejad et al., 2012; Ustinovichius et al., 2007; Taylan et al., 2014). Besides, the common topic is the risk assessment of construction projects, which is confirmed in the manuscripts by Zavadskas, Turskis, and Tamošaitiene (2010), Tamošaitiené, Zavadskas, and Turskis (2013), etc. The selection of a hotel construction project, i.e. of the appropriate type of the hotel to be constructed, is a problem that has not been paid sufficient scientific attention. Mainly, the selection of the hotel location, the evaluation of the energy efficiency of the hotel building and the evaluation of the quality of accommodation are the problems observed in manuscripts, as is previously stated.

In this manuscript, a framework for the selection of a hotel construction project based on the recently proposed WS PLP method is given. The main reason why this newly-developed method is being proposed herein is reflected in the unique characteristic of this method that the DM's preferences are concretely expressed through ppr values. In other words, this method directly incorporates the DM's attitude by the defining the desired value for each single criterion involved in the decision-making process. The applicability of the proposed framework is

Table 11. The ranking results obtained on the basis of the different values of $\gamma$

\begin{tabular}{|c|c|c|c|c|c|c|c|c|}
\hline & \multicolumn{2}{|c|}{$\gamma=0$} & \multicolumn{3}{c|}{$\gamma=0.5$} & \multicolumn{3}{c|}{$\gamma=1$} \\
\cline { 2 - 10 } & $S_{i}^{\prime}$ & Rank & $c_{i}$ & $S_{i}^{\prime}$ & Rank & $c_{i}$ & $S_{i}^{\prime}$ & Rank \\
\hline$A_{1}$ & 0.097 & 3 & 0.030 & 0.066 & 3 & 0.061 & 0.0360 & 1 \\
\hline$A_{3}$ & 0.206 & 2 & 0.110 & 0.096 & 2 & 0.219 & -0.0132 & 3 \\
\hline$A_{4}$ & 0.038 & 4 & 0.055 & -0.017 & 4 & 0.110 & -0.0719 & 4 \\
\hline$A_{5}$ & 0.222 & 1 & 0.111 & 0.111 & 1 & 0.222 & 0.0002 & 2 \\
\hline
\end{tabular}


demonstrated by using a real case study, which involves the five types of the hotels that should be built on Kopaonik Mountain in Serbia.

Different sets of criteria for the evaluation of construction projects have been proposed (Ginevičius \& Zubrecovas, 2009; Ha et al., 2015); because of the simplicity of the computational procedure, however, a set of the four criteria is used in this manuscript. Also, the performance ratings of the criteria are given as crisp numbers although the previously mentioned authors have discussed the application of fuzzy numbers in the construction project evaluation and selection process.

According to the fact that tourism is the economic sector that largely influences the economic development of a certain region, as well as of the entire country, the construction of new and an increase in the number of the existing accommodation facilities are necessary for enhancing tourism activities inside a territory. In order to make an optimal decision, the investor, i.e. the $D M$, can apply the proposed framework to available data, in which way he/she will facilitate the decision-making process focused on the selection of an appropriate hotel construction project to invest in and reduce the risk of making a bad decision. Speaking in scientific terms, proposing the usage of the newly-developed MCDM approach, whose possibilities are still not fully recognized and tested, especially in the field of the selection of a hotel construction project, presents the key novelty provided by this manuscript. Namely, the proposed framework gives the $D M$ a possibility of making a choice between the alternative that matches best the set preconditions, expressed through $p p r$ values, on the one hand, and that which has the best overall performance ratings of all other, which is a significant contribution made by the applied WS PLP method.

The principal constraint of this manuscript is a small number of the criteria involved in the evaluation. The proposed set of the criteria in the manuscripts by Ginevičius and Zubrecovas (2009) and Ha et al. (2015) could be the starting point for the formulation of a model incorporating a certain number of the criteria that would cover the different aspects of hotel construction, from technical to economic aspects, thus ensuring that the optimal hotel construction project to invest in will be selected.

Also, the proposed approach is based on the use of crisp numbers, which is not too adequate for real-world problems because every decision-making process is connected with the uncertainty and vagueness of input data. Taylan et al. (2014) and Ebrahimnejad et al. (2012) are among the authors who have elaborated upon the topic of the selection of construction projects in a fuzzy environment. It is recommended that future research should follow the direction of incorporating the intuitionistic fuzzy sets developed by Atanassov (1986) or the neutrosophic sets developed by Smarandache (2005) into the proposed framework and establishing a framework that would be convenient to use in an unpredictable and volatile business environment.

\section{References}

Abdi, H., \& Williams, L. J. (2010). Principal component analysis. Wiley Interdisciplinary Reviews: Computational Statistics, 2(4), 433-459. http://doi.org/10.1002/wics.101

Afshari, A., Mojahed, M., \& Yusuff, R. M. (2010). Simple additive weighting approach to personnel selection problem. International Journal of Innovation, Management and Technology, 1(5), 511-515.

Aksoy, S., \& Ozbuk, M. Y. (2017). Multiple criteria decision making in hotel location: does it relate to postpurchase consumer evaluations? Tourism Management Perspectives, 22, 73-81. https://doi.org/10.1016/j.tmp.2017.02.001

Atanassov, K. T. (1986). Intuitionistic fuzzy sets. Fuzzy Sets and Systems, 20(1), 87-96. https://doi.org/10.1016/S0165-0114(86)80034-3

Brans, J. P., \& Vincke, P. (1985). A preference ranking organization method: the PROMETHEE method for MCDM. Management Science, 31(6), 647-656. https://doi.org/10.1287/mnsc.31.6.647

Brauers, W. K. M., \& Zavadskas, E. K. (2010). Project management by MULTIMOORA as an instrument for transition economies. Technological and Economic Development of Economy, 16(1), 5-24. https://doi.org/10.3846/tede.2010.01

Chen, T. Y. (2012). Comparative analysis of SAW and TOPSIS based on interval-valued fuzzy sets: discussions on score functions and weight constraints. Expert Systems with Applications, 39(2), 1848-1861. https://doi.org/10.1016/j.eswa.2011.08.065

Child, D. (2006). The essentials of factor analysis ( $3^{\text {rd }} \mathrm{ed}$.). New York, NY: Continuum International Publishing Group.

Chou, S. Y., Chang, Y. H., \& Shen, C. Y. (2008). A fuzzy simple additive weighting system under group decision-making for facility location selection with objective/subjective attributes. European Journal of Operational Research, 189(1), 132-145. https://doi.org/10.1016/j.ejor.2007.05.006

Churchman, C. W., \& Ackoff, R. L. (1954). An approximate measure of value. Journal of the Operations Research Society of America, 2(2), 172-187. https://doi.org/10.1287/opre.2.2.172

Cloete, C. E., \& Venter, I. (2013). A framework for successful hotel developments. South African Journal of Economic and Management Sciences, 10(2), 223-237.

https://doi.org/10.4102/sajems.v10i2.584

Costello, A. B., \& Osborne, J. W. (2005). Best practices in exploratory factor analysis: four recommendations for getting the most from your analysis. Practical Assessment, Research \& Evaluation, 10(7), 1-9.

Ebrahimnejad, S., Mousavi, S. M., Tavakkoli-Moghaddam, R., Hashemi, H., \& Vahdani, B. (2012). A novel two-phase group decision making approach for construction project selection in a fuzzy environment. Applied Mathematical Modelling, 36(9), 4197-4217. https://doi.org/10.1016/j.apm.2011.11.050

Emir, O., \& Saraçli, S. (2014). Determination of the thermal hotel location: application of analytic hierarchy process. Tourism and Hospitality Management, 20(1), 71-83.

Fishburn, P. C. (1967). Additive utilities with incomplete product set: applications to priorities and assignments. Operations Research, 15(3), 537-542. https://doi.org/10.1287/opre.15.3.537

Ginevičius, R., \& Zubrecovas, V. (2009). Selection of the optimal real estate investment project basing on multiple criteria evaluation using stochastic dimensions. Journal of Business Economics and Management, 10(3), 261-270.

https://doi.org/10.3846/1611-1699.2009.10.261-270

Ha, J. H., Jeong, M., \& Lee, S. (2015). An analysis on the investment determinants for urban business hotel development. 
Korean Journal of Construction Engineering and Management, 16(4), 107-117. https://doi.org/10.6106/KJCEM.2015.16.4.107

Horwath HTL. (2009). Master Plan for the tourism destination Kopaonik - the final report for business master plan. Croatia: Horwath Consulting Zagreb (in Serbian).

Hotelling, H. (1933). Analysis of a complex of statistical variables into principal components. Journal of Educational Psychology, 24(6), 417-441. https://doi.org/10.1037/h0071325

Hsieh, L.-F., Lin, L.-H., \& Lin, Y.-Y. (2008). A service quality measurement architecture for hot spring hotels in Taiwan. Tourism Management, 29(3), 429-438.

https://doi.org/10.1016/j.tourman.2007.05.009

Hwang, C. L., \& Yoon, K. (1981). Multiple attribute decision making - methods and application. New York: Springer. https://doi.org/10.1007/978-3-642-48318-9

Jakimavičius, M., \& Burinskiene, M. (2009). A GIS and multi-criteria based analysis and ranking of transportation zones of Vilnius city. Technological and Economic Development of Economy, 15(1), 39-48. https://doi.org/10.3846/1392-8619.2009.15.39-48

Jato-Espino, D., Castillo-Lopez, E., Rodriguez-Hernandez, J., \& Canteras-Jordana, J. C. (2014). A review of application of multi-criteria decision making methods in construction. Automation in Construction, 45, 151-162.

https://doi.org/10.1016/j.autcon.2014.05.013

Jeong, J. S., García-Moruno, L., \& Hernández-Blanco, J. (2013). A site planning approach for rural buildings into a landscape using a spatial multi-criteria decision analysis methodology. Land Use Policy, 32, 108-118.

https://doi.org/10.1016/j.landusepol.2012.09.018

Jolliffe, I. T. (1986). Principal component analysis and factor analysis. In Principal component analysis, Springer series in statistics. New York, NY: Springer.

https://doi.org/10.1007/978-1-4757-1904-8_7

Kabak, Ö., \& Ruan, D. (2011). A comparison study of fuzzy MADM methods in nuclear safeguards evaluation. Journal of Global Optimization, 51(2), 209-226.

https://doi.org/10.1007/s10898-010-9601-1

Keršuliene, V., Zavadskas, E. K., \& Turskis, Z. (2010). Selection of rational dispute resolution method by applying new Stepwise Weight Assessment Ratio Analysis (SWARA). Journal of Business Economics and Management, 11(2), 243-258. https://doi.org/10.3846/jbem.2010.12

Krylovas, A., Zavadskas, E. K., \& Kosareva, N. (2016). Multiple criteria decision-making KEMIRA-M method for solution of location alternatives. Economic Research-Ekonomska Istraživanja, 29(1), 50-65. https://doi.org/10.1080/1331677X.2016.1152560

Li, G., Law, R., Vu, H. Q., \& Rong, J. (2013). Discovering the hotel selection preferences of Hong Kong inbound travelers using the Choquet Integral. Tourism Management, 36, 321330. https://doi.org/10.1016/j.tourman.2012.10.017

Lin, C.-T., Lee, C., \& Wu, C.-S. (2009). Optimizing a marketing expert decision process for the private hotel. Expert Systems with Applications, 36(3), 5613-5619.

https://doi.org/10.1016/j.eswa.2008.06.113

Manning, C., O’Neill, J. W., Singh, A. J., Hood, S., Liu, C., \& Bloom, B. A. (2015). The emergence of hotel/lodging real estate research. Journal of Real Estate Literature, 23(1), 1-26. https://doi.org/10.5555/0927-7544.23.1.1

Newell, G., \& Seabrook, R. (2006). Factors influencing hotel investment decision making. Journal of Property Investment \& Finance, 24(4), 279-294.

https://doi.org/10.1108/14635780610674499

Oltean-Dumbrava, C., Watts, G., \& Miah, A. (2016). Towards a more sustainable surface transport infrastructure: a case study of applying multi criteria analysis techniques to assess the sustainability of transport noise reducing devices. Journal of Cleaner Production, 112, 2922-2934.

https://doi.org/10.1016/j.jclepro.2015.09.096

Opricovic, S. (1998). Multicriteria optimization of civil engineering systems. Belgrade: Faculty of Civil Engineering (in Serbian).

Park, D. B., Kim, K. H., \& Choo, H. (2014). The development of quality standards for rural farm accommodations: a case study in South Korea. Journal of Hospitality \& Tourism Research, 41(6), 673-695. https://doi.org/10.1177/1096348014550871

Rikhtegar, N., Mansouri, N., Ahadi Oroumieh, A., YazdaniChamzini, A., Zavadskas, E. K., \& Kildienè, S. (2014). Environmental impact assessment based on group decisionmaking methods in mining projects. Economic ResearchEkonomska Istraživanja, 27(1), 378-392. https://doi.org/10.1080/1331677X.2014.966971

Roy, B. (1991). The outranking approach and the foundation of ELECTRE methods. Theory and Decision, 31(1), 49-73. https://doi.org/10.1007/BF00134132

Saaty, T. L. (1980). The Analytic Hierarchy Process: planning, priority setting, resource allocation. New York: McGraw-Hill.

Shakouri, H., Nabaee, M., \& Aliakbarisani, S. (2014). A quantitative discussion on the assessment of power supply technologies: DEA (data envelopment analysis) and SAW (simple additive weighting) as complementary methods for the "Grammar". Energy, 64, 640-647. https://doi.org/10.1016/j.energy.2013.10.022

Shirouyehzad, H., Lotfi, F. H., Arabzad, S. M., \& Dabestani, R. (2013). An AHP/DEA ranking method based on service quality approach: a case study in hotel industry. International Journal of Productivity and Quality Management, 11(4), 434445. https://doi.org/10.1504/IJPQM.2013.054269

Smarandache, F. (2005). Neutrosophic set-a generalization of the intuitionistic fuzzy set. International Journal of Pure and Applied Mathematics, 24(3), 287-297.

Spearman, C. (1904). General intelligence, objectively determined and measured. The American Journal of Psychology, 15(2), 201-292. https://doi.org/10.2307/1412107

Stanujkic, D., Magdalinovic, N., \& Jovanovic, R. (2013). A multiattribute decision making model based on distance from decision maker's preferences. Informatica, 24(1), 103-118.

Stanujkic, D., \& Zavadskas, E. K. (2015). A modified weighted sum method based on the decision-maker's preferred levels of performances. Studies in Informatics and Control, 24(4), 461-470. https://doi.org/10.24846/v24i4y201510

Taylan, O., Bafail, A. O., Abdulaal, R. M., \& Kabli, M. R. (2014). Construction projects selection and risk assessment by fuzzy AHP and fuzzy TOPSIS methodologies. Applied Soft Computing, 17, 105-116. https://doi.org/10.1016/j.asoc.2014.01.003

Tamošaitiene, J., Zavadskas, E. K., \& Turskis, Z. (2013). Multicriteria risk assessment of a construction project. Procedia Computer Science, 17, 129-133. https://doi.org/10.1016/j.procs.2013.05.018

Thurstone, L. L. (1935). The vectors of mind: multiple-factor analysis for the isolation of primary traits. Chicago: University Chicago Press. https://doi.org/10.1037/10018-000

Thurstone, L. L. (1947). Multiple-factor analysis. Chicago: University Chicago Press.

Tseng, M.-L. (2009). Using the extension of DEMATEL to integrate hotel service quality perceptions into a cause-effect model in uncertainty. Expert Systems with Applications, 36(5), 9015-9023. https://doi.org/10.1016/j.eswa.2008.12.052

Ustinovichius, L., Zavadkas, E. K., \& Podvezko, V. (2007). Application of a quantitative multiple criteria decision making 
(MCDM-1) approach to the analysis of investments in construction. Control and Cybernetics, 36(1), 251-268.

Varini, K., Scaglione, M., \& Schegg, R. (2011). Distribution channel and efficiency: an Analytic Hierarchy Process approach. Information and Communication Technologies in Tourism, 2011, 547-558. https://doi.org/10.1007/978-3-7091-0503-0_44

Wang, Y. J. (2015). A fuzzy multi-criteria decision-making model based on simple additive weighting method and relative preference relation. Applied Soft Computing, 30, 412-420. https://doi.org/10.1016/j.asoc.2015.02.002

Wang, P., Zhu, Z., \& Wang, Y. (2016). A novel hybrid MCDM model combining the SAW, TOPSIS and GRA methods based on experimental design. Information Sciences, 345, 27-45. https://doi.org/10.1016/j.ins.2016.01.076

Wu, C.-S., Lin, C.-T., \& Lee, C. (2010). Optimal marketing strategy: a decision-making with ANP and TOPSIS. International Journal of Production Economics, 127(1), 190-196. https://doi.org/10.1016/j.ijpe.2010.05.013

Xu, P., \& Chan, E. H. W. (2013). ANP model for sustainable Building Energy Efficiency Retrofit (BEER) using Energy Performance Contracting (EPC) for hotel buildings in China. Habitat International, 37, 104-112.

https://doi.org/10.1016/j.habitatint.2011.12.004
Zavadskas, E. K., Kaklauskas, A., \& Sarka, V. (1994). The new method of multi-criteria complex proportional assessment of projects. Technological and Economic Development of Economy, 1(3), 131-139.

Zavadskas E. K., Ustinovichius, L., \& Stasiulionis, A. (2004). Multicriteria valuation of commercial construction projects for investment purposes. Journal of Civil Engineering and Management, 10(2), 151-166. https://doi.org/10.1080/13923730.2004.9636299

Zavadskas, E. K., \& Turskis, Z. (2010). A new Additive Ratio Assessment (ARAS) method in multicriteria decision-making. Technological and Economic Development of Economy, 16(2), 159-172. https://doi.org/10.3846/tede.2010.10

Zavadskas, E. K., Turskis, Z., \& Tamošaitiene, J. (2010). Risk assessment of construction projects. Journal of Civil Engineering and Management, 16(1), 33-46. https://doi.org/10.3846/jcem.2010.03

Zavadskas, E. K., Turskis, J., Antucheviciene, A., \& Zakarevicius, A. (2012). Optimization of weighted aggregated sum product assessment. Elektronika ir elektrotechnika, 122(6), 3-6. https://doi.org/10.5755/j01.eee.122.6.1810 